NASA/TM-2004-212391

\title{
Velocity and Temperature Measurement in Supersonic Free Jets Using Spectrally Resolved Rayleigh Scattering
}

J. Panda

Modern Technologies Corporation, Middleburg Heights, Ohio

R.G. Seasholtz

Glenn Research Center, Cleveland, Ohio 
Since its founding, NASA has been dedicated to the advancement of aeronautics and space science. The NASA Scientific and Technical Information (STI) Program Office plays a key part in helping NASA maintain this important role.

The NASA STI Program Office is operated by Langley Research Center, the Lead Center for NASA's scientific and technical information. The NASA STI Program Office provides access to the NASA STI Database, the largest collection of aeronautical and space science STI in the world. The Program Office is also NASA's institutional mechanism for disseminating the results of its research and development activities. These results are published by NASA in the NASA STI Report Series, which includes the following report types:

- $\quad$ TECHNICAL PUBLICATION. Reports of completed research or a major significant phase of research that present the results of NASA programs and include extensive data or theoretical analysis. Includes compilations of significant scientific and technical data and information deemed to be of continuing reference value. NASA's counterpart of peerreviewed formal professional papers but has less stringent limitations on manuscript length and extent of graphic presentations.

- TECHNICAL MEMORANDUM. Scientific and technical findings that are preliminary or of specialized interest, e.g., quick release reports, working papers, and bibliographies that contain minimal annotation. Does not contain extensive analysis.

- CONTRACTOR REPORT. Scientific and technical findings by NASA-sponsored contractors and grantees.
- CONFERENCE PUBLICATION. Collected papers from scientific and technical conferences, symposia, seminars, or other meetings sponsored or cosponsored by NASA.

- SPECIAL PUBLICATION. Scientific, technical, or historical information from NASA programs, projects, and missions, often concerned with subjects having substantial public interest.

- TECHNICAL TRANSLATION. Englishlanguage translations of foreign scientific and technical material pertinent to NASA's mission.

Specialized services that complement the STI Program Office's diverse offerings include creating custom thesauri, building customized databases, organizing and publishing research results ... even providing videos.

For more information about the NASA STI Program Office, see the following:

- Access the NASA STI Program Home Page at http://www.sti.nasa.gov

- E-mail your question via the Internet to help@sti.nasa.gov

- Fax your question to the NASA Access Help Desk at 301-621-0134

- Telephone the NASA Access Help Desk at 301-621-0390

- Write to:

NASA Access Help Desk

NASA Center for AeroSpace Information 7121 Standard Drive

Hanover, MD 21076 
NASA/TM-2004-212391

AIAA-99-0296

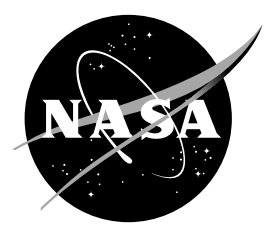

\title{
Velocity and Temperature Measurement in Supersonic Free Jets Using Spectrally Resolved Rayleigh Scattering
}

\author{
J. Panda \\ Modern Technologies Corporation, Middleburg Heights, Ohio \\ R.G. Seasholtz \\ Glenn Research Center, Cleveland, Ohio
}

Prepared for the

37th Aerospace Sciences Meeting and Exhibit

sponsored by the American Institute of Aeronautics and Astronautics

Reno, Nevada, January 11-14, 1999

National Aeronautics and

Space Administration

Glenn Research Center 


\section{Acknowledgments}

The authors would like to acknowledge the skill and dedication of Mr. Wentworth T. John in setting up the optical system. His skill in working with the Fabry-Perot interferometer was indispensable.

This report has been prepared by using provided electronic files.

rar

$\begin{array}{lr} & \text { Available from } \\ \text { NASA Center for Aerospace Information } & \text { National Technical Information Service } \\ \text { 7121 Standard Drive } & 5285 \text { Port Royal Road } \\ \text { Hanover, MD 21076 } & \text { Springfield, VA 22100 }\end{array}$




\title{
Velocity and Temperature Measurement in Supersonic Free Jets Using Spectrally Resolved Rayleigh Scattering
}

\author{
J. Panda \\ Modern Technologies Corporation \\ Middleburg Heights, Ohio 44130 \\ R.G. Seasholtz \\ National Aeronautics and Space Administration \\ Glenn Research Center \\ Cleveland, Ohio 44135
}

\begin{abstract}
The flow fields of unheated, supersonic free jets from convergent and convergent-divergent nozzles operating at $\mathrm{M}=0.99,1.4$ and 1.6 were measured using spectrally resolved Rayleigh scattering technique. The axial component of velocity and temperature data as well as density data obtained from a previous experiment are presented in a systematic way with the goal of producing a data base useful for validating computational fluid dynamics codes. The Rayleigh scattering process from air molecules provides a fundamental means of measuring flow properties in a non-intrusive, particle free manner. In the spectrally resolved application, laser light scattered by the air molecules is collected and analyzed using a Fabry-Perot interferometer (FPI). The difference between the incident laser frequency and the peak of the Rayleigh spectrum provides a measure of gas velocity. The temperature is measured from the spectral broadening caused by the random thermal motion and density is measured from the total light intensity. The present point measurement technique uses a $\mathrm{CW}$ laser, a scanning Fabry-Perot interferometer (FPI) and photon counting electronics. The $1 \mathrm{~mm}$ long probe volume is moved from point to point to survey the flow fields. Additional arrangements were made to remove particles from the main as well as the entrained flow and to isolate FPI from the high sound and vibration levels produced by the supersonic jets. In general, velocity is measured within $\pm 10 \mathrm{~m} / \mathrm{s}$ accuracy and temperature within $\pm 10^{\circ} \mathrm{K}$ accuracy.
\end{abstract}

\section{INTRODUCTION}

With the advent of the High Speed Civil Transport program, the flow field of the supersonic free jets has generated renewed interest. The sound generated from such jets is of primary importance. In contrast to a vast amount of acoustic information gathered over the last 4 decades, there exists very little information on the flow field of such jets. The present work is a part of a collaborative program to predict supersonic jet noise using advanced computational techniques. The goal of the experimental part is to provide a reliable and accurate database, which can be used to validate the computational fluid dynamics and aeroacoustics codes.

The lack of experimental data is primarily due to the problems in using the traditional experimental tools which are either too intrusive or use seed particles. Moreover, unlike its incompressible counterpart, the compressibility effects present in a high Mach number jet require a description of the thermodynamic quantities, such as density and temperature in addition to velocity. Simultaneous measurement of fluid dynamic and thermodynamic quantities is all but impossible using the traditional probes. The intrusive probes, such as the static and total pressure tubes or a hot-wire probe cause significant alterations that can be easily detected as a change in the noise emitted by the jet. The optical seed particle based techniques, such as the Laser-Doppler velocimetry (LDV) and Particle Image Velocimetry (PIV) are partially successful in providing time averaged velocity data ${ }^{1,2,3}$. 
However, various biasing errors encountered in turbulent flows, problems associated with seed particles passing through shock waves, beam steering effects from sharp density gradients and problems in measuring high Doppler frequency shift using commercially available electronics make such techniques either difficult or of doubtful value in supersonic flows. The Rayleigh scattering technique, on the other hand, depends on the light scattering from air molecules. Since, no seed particles are used and only a single beam is necessary, many problems associated with LDV and PIV can be overcome. Moreover, information is obtained directly from the molecular distributions; therefore, the Rayleigh scattering technique is a more fundamental way of measuring flow properties.

In the last few years, a number of Rayleigh scattering based optical flow diagnostic techniques had been developed. To measure flow velocity and temperature one needs to spectrally resolve the Rayleigh scattered light, which has been pursued by two means. The first method is to use a tunable laser and molecular absorption filters, such as the hyperfine absorption lines of Iodine vapors (Forkey, Lempert \& Miles ${ }^{4}$, Elliot $\&$ Samimy $^{5}$, Seasholtz, Buggele \& Reeder ${ }^{6}$ and others). The second method is to use a FabryPerot interferometer (Seasholtz, Zupanc \& Schneider ${ }^{7}$, Snyder et $a l^{8}$. Pitz, Cattolica \& Talbot ${ }^{9}$, Lock, Seasholtz \& John ${ }^{10}$ and others). The two methods have their own advantages and disadvantages. The present work follows the second methodology, which perhaps is better suited to obtain unsteady time accurate measurements, a long-term goal of the current program. A combination of narrow line width continuous wave laser, scanning Fabry-Perot interferometer and photon counting electronics is used to perform point measurement of velocity and temperature in supersonic flows. It should be mentioned here that a simpler version of the setup (without the Fabry-Perot interferometer) has been successfully used to measure density in similar flow fields. This has been reported earlier (Panda \& Seasholtz ${ }^{11}$ ).
Since it is relatively easy to produce a small supersonic jet in the laboratory environment, free jets have been common test grounds for various optical techniques including a few variations of the Rayleigh scattering based techniques ${ }^{4,5}$. The velocity and density data reported in the above studies are from a few points, and are insufficient to characterize the global flow field, which is the motivation of the current study. The primary attention of the earlier work was a demonstration of the proof of principle where the optical setup is at primary focus and the purpose of a tiny free jet is to create a supersonic flow. In the present work additional complexities, such as high noise level, vibration, particle contamination, condensation etc. present in a comparatively larger facility are addressed.

In addition to the velocity and temperature measurements density data obtained from the same flowfield are also presented in this paper for the sake of completeness. Although it is straightforward to measure all three quantities simultaneously, the current setup was used to measure velocity and temperature only and density values were measured separately ${ }^{11,12}$. For density data, intensity of the total scattered light needs to be measured. Since the Fabry-Perot interferometer is unnecessary for this purpose, a higher accuracy level is achievable in separate measurement.

\section{THEORY OF THE MEASUREMENT TECHNIQUE}

Rayleigh scattering is a consequence of elastic light scattering process from gas molecules. Traditionally, molecular scattering has been separated into two regimes, kinetic and hydrodynamic (also known as Brillouin scattering) based on the relative importance of scattering from the very high frequency density fluctuations with a characteristic length scale comparable to the molecular free path. For the present experimental conditions, involving not very high temperature and pressure and approximately $90^{\circ}$ scattering, the influence of the Brillouin scattering is relatively small and the scattering process can be approximated as a sum of contributions from individual molecules present 
at the probe volume. In this limit, the light scattered from each of the molecules is Doppler shifted according to its velocity and direction.

A simplistic description of the measurement process using laser induced Rayleigh scattering is schematically shown in Fig. 1. Since the Doppler shift frequency is of the order of a few GigaHertz, a narrow line width (of the order of $10 \mathrm{MHz}$ ) incident laser beam is necessary to resolve Rayleigh spectrum. In the case of a moving gas media, the bulk motion is superimposed on the random velocity of the individual molecules; therefore separation between the peaks of the incident laser line and the Rayleigh spectrum provides a measure of the bulk velocity. The Full Width at Half Maxima (FWHM) depends on the spread of molecular motion and, therefore, is a measure of gas temperature. Finally, the total light under the Rayleigh spectrum is proportional to the molecular number density and provides a measure of gas density. Therefore, a single Rayleigh spectrum carries information of one component of gas velocity, bulk temperature and bulk density.

Figure 2 presents a scattering diagram, where $\mathbf{k}_{\mathrm{i}}$ is the incident wave vector, $\mathbf{k}_{\mathrm{s}}$ is the scattered wave vector pointing towards the collection optics, $\theta_{\mathrm{s}}$ is the scattering angle and, $\mathbf{k}$ $=\mathbf{k}_{\mathrm{s}}-\mathbf{k}_{\mathrm{i}}$, is the scattering vector. For $\mathrm{k}_{\mathrm{s}} \approx \mathrm{k}_{\mathrm{i}}$, the magnitude of the scattering vector becomes $k=2$ $\mathrm{k}_{\mathrm{i}} \sin \left(\theta_{\mathrm{s}} / 2\right)$, and the Doppler shift from the bulk velocity $U$ of the flow is

$$
\mathrm{f}_{\mathrm{d}}=\frac{\mathbf{k} \cdot \mathbf{U}}{2 \pi}=\frac{2 \mathrm{U} \cos \Phi \sin \left(\frac{\theta_{\mathrm{s}}}{2}\right)}{\lambda_{\mathrm{i}}}
$$

where, $\Phi$ is the angle between the scattering vector $\mathbf{k}$ and the velocity vector $\mathbf{U}$, and $\lambda_{i}$ is the wavelength of the incident light. The same Doppler shift principle applies to the individual molecules as well. The gas molecules are assumed to have a Maxwellian velocity distribution $\mathrm{f}(\mathrm{V})$ :

$$
f(V) d^{3} V=\frac{n}{\pi^{3 / 2} a^{3}} \exp \left(-\frac{(V-U)^{2}}{a^{2}}\right) d^{3} V,
$$

where, $\mathrm{n}=$ the molecular number density, $\mathrm{a}=$ "most probable speed" $=\left(2 \mathrm{k}_{\mathrm{B}} \mathrm{T} / \mathrm{m}\right)^{1 / 2}, \mathrm{k}_{\mathrm{B}}$ is the
Boltzmann's constant, $\mathrm{m}$ is molecular mass and $\mathrm{T}$ is gas temperature. If Brillouin scattering has negligible contribution, then the bandwidth (FWHM) of Rayleigh spectrum, due to the Maxwellian molecular velocity distribution becomes:

$$
\Delta \mathrm{f}=0.265 \mathrm{k}\left(\frac{2 \mathrm{k}_{\mathrm{B}} \mathrm{T}}{\mathrm{m}}\right)^{1 / 2} .
$$

Clearly, for a fixed optical setup (k fixed) and a given gas mixture ( $\mathrm{m}$ fixed) the bandwidth of Rayleigh spectrum is proportional to the square root of temperature.

It should be pointed out here that the above description of velocity, temperature and density measurement is somewhat simplistic. The Tenti S6 model $^{13}$ used in data analysis considers both Rayleigh and Brillouin parts of scattering. Instead of just measuring the FWHM of Rayleigh spectra the Tenti's model function is fitted through experimental data to improve accuracy of temperature measurement. Since density depends on the total scattered light, no spectral analysis is required.

Fabry-Perot Interferometer: The high resolution required in Rayleigh spectroscopy necessitates the use of a Fabry-Perot interferometer ${ }^{14,15}$ (FPI). It acts as a light filter whose transmittance is dependent on the frequency $f$ of the incident light, the angle $\mathrm{q}$ of the incident light with the optical axis, the refractive index $\mu$ in the medium between two flat mirrors and the mirror separation d (Fig. $3)$. In an ideal no loss situation the transmittance is given by the Airy function:

$$
\mathrm{I}_{\mathrm{t}}=\left[1+\left(\frac{2 \mathrm{~N}}{\pi}\right)^{2} \sin ^{2}\left(\frac{2 \pi \mu \mathrm{d} \cos \theta}{\lambda_{\mathrm{i}}}\right)\right]^{-1},
$$

where, $\mathrm{N}$ is the interferometer finesse that determines the sharpness of the filter roll-off; a higher finesse translates into a sharper roll-off. For an ideal interferometer finesse is a function of the mirror reflectance only, however; in reality factors such as imperfections in the mirror coating, misalignment of the optical train, vibration and noise (both acoustic and electronic) degrades the finesse. An incorrect finesse value affects the measurement accuracy and one needs to monitor 
finesse continuously during the course of experiment. Figure 3 shows that the light coming off an optical fiber is imaged through the FPI using a focusing and a fringe forming lens. As light from different part of the fiber makes different $\theta$ angle with the optical axis, even a single frequency light is imaged as concentric rings at the image plane. In the present setup, to measure frequency of incoming light, the FPI was operated in the scanning mode, that is, the mirror separation $\mathrm{d}$ is continuously changed by moving one of the two mirrors. A scan that changes the mirror spacing by $\lambda_{\mathrm{i}} / 2$ causes the FPI output to move from one transmission peak to the next; a separation represented by the free spectral range of the interferometer:

$$
\text { Free spectral range }=\frac{\mathrm{c}}{2 \mathrm{~d}},
$$

where, $\mathrm{c}$ is the speed of light. As the plates are scanned the fringes formed at the image plane move inward. In practice, additional spurious concentric rings are found outside the fiber face. Based upon the optimization calculation of Hernandez ${ }^{15}$ the diameter of the pinhole, placed at the image plane, is chosen to be $30 \%$ of the first fringe diameter.

The frequency spectrum $S(v)$ measured using the Fabry-Perot interferometer is a convolution of the actual Rayleigh scattering spectrum $\mathrm{S}_{\mathrm{R}}(\mathrm{n})$ and the characteristic of FPI filter represented as a Instrument function $\mathrm{I}(v)$ :

$$
\mathrm{S}_{\mathrm{M}}(v)=\mathrm{G}_{\mathrm{R}} \int \mathrm{I}\left(v^{\prime}\right) \mathrm{S}_{\mathrm{R}}\left(v-v^{\prime}\right) \mathrm{d} v^{\prime}+\mathrm{B},
$$

where, $G_{R}$ is the total Rayleigh scattered power and $\mathrm{B}$ is the uniform background from the photomultiplier dark current. The laser line width, finesse and free spectral range are included in the instrument function. Note that frequency is represented as $v$ which is a relative scale referred to an arbitrary reference value. This is allowable since the frequency difference between the incident and the scattered light is of interest for aerodynamic measurements. The instrument function also includes the location of the transmission peak, relative to which the Doppler shift is measured. Since the instrument function tends to change with a small drift in the ambient condition and the instrument controlling electronics, it has to be monitored continuously. Note that, unlike density measurement, velocity and temperature measurement using Rayleigh scattering technique do not require any fluid dynamic calibration. However, the slow drift of FPI and the laser line requires reevaluation of the instrument function before each Rayleigh spectrum is acquired.

\section{EXPERIMENTAL SETUP}

The experiments were conducted at the NASA Glenn Research Center. Two convergentdivergent nozzles were designed using the method of characteristics for fully expanded operating Mach numbers of $\mathrm{M}=1.4$ and 1.8. Later on, centerline surveys showed that the least shock operation is achieved at respectively, $\mathrm{M}=1.395$ and 1.795. The operating conditions are provided in Table I. The exit diameter for both nozzles is $25.45 \mathrm{~mm}$ (1.002 inches). Figure 4 shows a schematic of a CD nozzle block. The axial and radial coordinates of the inside contour of the $\mathrm{C}-\mathrm{D}$ nozzles are provided in Table II. In addition a convergent nozzle of $25.4 \mathrm{~mm}$ exit diameter was used to produce $\mathrm{M}=0.99$ jet. Figure 5 shows a schematic of the Rayleigh scattering setup. An additional view showing a part of the arrangement around the nozzle block is shown in photograph 6 . The supply air was unheated with an average total temperature of $24^{\circ}$ Celsius. This was also the average ambient temperature.

Optical configuration: In essence, the Rayleigh scattering setup consists of a continuous laser beam focused at a point (probe volume) in the flow field; the light scattered by the air molecules is collected, analyzed by a Fabry-Perot interferometer and measured by a photomultiplier tube. The extremely high noise level produced by the supersonic jets was a concern for the stable operation of the laser and the Fabry-Perot interferometer (FPI). The optical alignment of the flat mirrors present in the interferometer is especially sensitive to noise and vibration. Any vibration capable of producing a few nanometers of displacement in the mirror alignment creates a 
measurable degradation in finesse. Since, a successful operation of the Rayleigh scattering system was critically dependent on the proper management of the noise and vibration issue, it was decided to split the optical arrangement into 3 parts. The first part is the laser light source: a Neodymium Vanadate (Nd:YVO4) laser that produced 5Watt power in 532 nanometer wavelength and has a narrow $100 \mathrm{MHz}$ bandwidth was used. The laser source was kept in the same room that houses the jet facility. However to ensure stable operation an anechoic box was built around the laser and the light was passed through 30 meter long, $0.365 \mathrm{~mm}$ core diameter, multimode, fiber-optic cable (Fig. 5).

The second part consisted of an arrangement built around the jet facility and mounted on a two-axis traversing mechanism that facilitated point by point movement along the flow (x-axis) and transverse (r-axis) directions (Figs. 5, 6 ). The transmitting side of the optical train was designed to focus the incident beam at the measurement volume using an $\mathrm{f} / 2,80 \mathrm{~mm}$ diameter and an $\mathrm{f} / 3.3,82 \mathrm{~mm}$ diameter achromatic lens. The scattered light was collected from a scattering angle $\theta_{\mathrm{s}}=85^{\circ}$ (Fig. 2) using identical lenses and was coupled to a $0.55 \mathrm{~mm}$ core diameter fiber. The optical configuration was designed to align the scattering vector along the jet flow direction so that the axial component of the velocity vector is measured directly. The f/3.3 collection lens fixed the collection aperture. The laser power delivered to the probe volume was 3.5 Watts. However, the laser light at the probe volume was randomly polarized by its transmission through the optical fiber. Thus, because of the polarization sensitivity of the Rayleigh scattering, only about $1 / 2$ of the laser power was effectively used. The core diameter of the collection fiber and the magnification factor of the collecting lenses fixed the probe volume length to $1.03 \mathrm{~mm}$. The diameter of the beam waist was $0.16 \mathrm{~mm}$.

As mentioned earlier, the Fabry-Perot alignment and the laser operation require constant monitoring in the form of evaluating the instrument function $\mathrm{I}(\mathrm{v})$ before analyzing an Rayleigh spectrum. For this purpose a small amount of incident laser light coming off the transmitting fiber is coupled to the collection fiber using an additional reference fiber (Fig.5). A small part of retro-reflection from the transmitting lenses is coupled at the input of the reference fiber. The output is mounted on a pneumatic actuator that can be moved to bring the fiber end in front of the receiving fiber. At this position Rayleigh scattered light is blocked and the receiving fiber transmits a small amount of the incident laser light. This light is analyzed by the FPI to determine $I(v)$. To couple Rayleigh scattered light the actuator is moved back. The actuator motion was slowed down using additional pneumatic control to minimize vibration and shock from quick deployment and retracing. The on-off motion of the actuator was controlled through a 5V TTL signal. To minimize stray light, the incident beam was directed into a beam dump. A similar arrangement was made in the collection side to provide a dark background. The jet operating conditions were monitored via a pressure transducer and a thermocouple probe placed in the jet plenum.

The third part of the overall setup consisted of the interferometric arrangement for the spectral analysis of the collected light. This was kept in an isolated loft in an adjoining room that was free from the high noise level produced by the jet. The collected light was brought from the test cell using a fiber-optic cable. The Fabry-Perot interferometer used is a commercially available one with $70 \mathrm{~mm}$ diameter mirrors, $\lambda / 200$ flatness and $90 \%$ reflectivity. The mirrors are set at $20.3 \mathrm{~mm}$ spacing, producing a free spectral range (FSR) of 7.4 Ghz. The frequency range scanned was about 2 FSR which correspond to a change in the mirror spacing of $\lambda$. The light coming out of the collection fiber is collimated using a $\mathrm{f} / 2,80 \mathrm{~mm}$ diameter achromatic lens into the FPI, and an $\mathrm{f} / 5$ $100 \mathrm{~mm}$ diameter fringe forming lens was used to focus FPI output on the pinhole. Light from the pinhole is once again collimated and measured using a thermo-electrically cooled photomultiplier tube.

A few other hurdles had to be overcome before the Rayleigh scattering technique could be 
successfully implemented. The most difficult one arose from the dust particles. Since particle (Mie) scattering is a few orders of magnitude stronger than the Rayleigh scattered light, presence of dust particles can completely swamp the Rayleigh signature. The dry air, supplied to the rig from a central high pressure facility, was passed through two sets of filters for dust removal. This made the primary jet air very clean; however particles from the entrained air made density measurement impossible in the jet shear layer. To mitigate this problem, an air filter system that provided dust free air in the jet neighborhood was installed. The clean air was routed via a flexible duct and exhausted vertically at a very low speed $(\sim 8 \mathrm{~m} / \mathrm{s})$ through a $30.5 \mathrm{~cm} \mathrm{X} 38 \mathrm{~cm}$ hood over the nozzle block (figs. 5, 6). The clean air from the hood flows in a vertical direction, normal to the main jet, and in effect, creates a crossflow situation. However, any perturbation to the supersonic jet is expected to be minimal due to the very low crossflow velocity.

The electrical circuit supplying actuation voltage (ramp signal) for the piezo-electric elements in the FPI was found to be susceptible to electrical noise in the house power supply. A line filter circuitry has to be used to eliminate such noise.

Data acquisition and processing: The low level of the scattered light called for a photon counting system and the cooled photomultiplier tube (PMT) was especially suitable. The PMT output was terminated on a $50 \mathrm{Ohm}$ terminator, amplified by a wide bandwidth electronic amplifier and the final pulse counting was performed through a photon counter. Typically, the FPI was set to scan two free spectral ranges over half a second time, which was divided into 100 smaller intervals (bins) and the number of photoelectrons arriving during each of the smaller intervals were counted. To reduce the effect of random noise in scanning and to improve photon count averaging over 4 successive scans were performed. Data acquisition at each measurement station was a two step process.
First a reference spectrum was obtained to determine the instrument function. For this purpose the actuator was moved to position the output end of the reference fiber in front of the receiving fiber. A small amount of incident laser light was transmitted to the Fabry-Perot interferometer and a reference spectrum was collected (Fig. 7a). In the second step the pneumatic actuator was retracted back, allowing Rayleigh scattered light to be transmitted through the receiving fiber and a Rayleigh spectrum was collected (Fig. 7b). Such a two-step acquisition process was repeated for all data points while the probe volume was moved from point to point in the flow field.

The post-processing of the acquired data is also a two step process. First a model Airy function (similar to that of equation 4) is fitted through the reference signal using a maximum likelihood curve fitting procedure to obtain the instrument function. Next the Rayleigh spectrum is fitted to a model function represented by equation (6) using the same curve fitting procedure where Poisson's statistics are assumed for the photon arrival rate. For the Rayleigh spectrum Tenti's S6 model was used ${ }^{13}$. The curve fitting procedure provides estimates of the parameters of interest: velocity, gas temperature, a relative measure of gas number density $\left(\mathrm{G}_{\mathrm{R}}\right.$ in equation 6), and uniform background (B in equation 6).

\section{RESULTS AND DISCUSSION}

Validation: Figure 8 shows some measured data obtained from the core region $(\mathrm{r} / \mathrm{D}=0, \mathrm{x} / \mathrm{D}=2.5$, where $\mathrm{r}$ represents radial distance from the jet core, $\mathrm{x}$ is the downstream distance from the nozzle exit and $\mathrm{D}$ is the nozzle exit diameter) of subsonic free jets. The jet core is particularly suitable for validation as the flow properties remain uniform. The jet Mach number $M$ was changed by changing the plenum pressure $\mathrm{P}_{0}$. The axial velocity $\mathrm{u}$, temperature $t$ and density $r$ at the core of a free jet emitting from an convergent nozzle can be determined easily using isentropic relations until a choked condition $(\mathrm{M} \leq 1)$ is reached: 


$$
\begin{aligned}
\frac{\mathrm{P}_{0}}{\mathrm{P}_{\mathrm{amb}}} & =\left(1+\frac{\gamma-1}{2} \mathrm{M}^{2}\right)^{\frac{\gamma}{\gamma-1}} \\
\frac{\mathrm{t}}{\mathrm{T}_{0}} & =\left(1+\frac{\gamma-1}{2} \mathrm{M}^{2}\right) \\
\mathrm{u} & =\mathrm{M} \sqrt{\gamma \mathrm{Rt}} \\
\rho & =\frac{\mathrm{P}_{0}}{\mathrm{R}_{0}}\left(\frac{\mathrm{P}_{0}}{\mathrm{P}_{\mathrm{amb}}}\right)^{-\frac{1}{\gamma}},
\end{aligned}
$$

where, $\mathrm{T}_{0}$ is the plenum temperature, $\mathrm{P}_{\mathrm{amb}}$ is the ambient pressure, $\mathrm{R}$ is the universal gas constant and $\mathrm{g}$ is the ratio of specific heats.

The velocity and temperature data follows the expected values closely. At a fixed jet operating condition multiple Rayleigh spectra were obtained to determine repeatability which also provides an uncertainty estimate. It is found that the velocity data are in general repeatable within $\pm 10 \mathrm{~m} / \mathrm{s}$. The measured temperature is found to be somewhat lower than the actual temperature; the bias is about $-8^{\circ} \mathrm{K}$, and the superimposed random uncertainty is additional $\pm 8^{\circ} \mathrm{K}$. A percentage uncertainty estimate is perhaps inappropriate; as there is no systematic uncertainty, that is, the random error is found to be independent of the measured velocity or temperature. The primary sources of uncertainty are traced to the variations in incident laser frequency and FPI mirror scanning using piezoelectric transducers (PZT). The shot noise contribution is expected to be small due to the relatively high rate of photon arrival. Some of the data points presented later in this paper are affected by the presence of small amount of dust particles in the flow. The dust particles deteriorate temperature measurements while velocity data remain unaffected. Noise associated with the mirror scanning was found to degrade the instrument finesse and had contributed towards the uncertainty in fitting model functions. Finally, the uncertainty level associated with the density measurements is the lowest, $\pm 1 \%$, among all.

Fig. 9 shows centerline decay of velocity, temperature and density measured in the $\mathrm{M}=0.99$ jet. The density measurements are from a different Rayleigh scattering arrangement ${ }^{11,12}$. In the present unheated jets isentropic expansion through the nozzle cools the core flow below ambient and increases density above ambient condition. Mixing with the ambient air, however, causes a rise in temperature and fall in density, both of which approach the ambient condition. These features are seen in the presented data. The uncertainty in velocity and temperature measurement has given rise to the random data scatter. There are no shock cells in this jet as apparent from the density data that has the lowest uncertainty level.

Fig. 10 presents radial surveys obtained from various axial stations in the same $M=0.99$ jet emitting from a convergent nozzle. All 3 profiles - velocity, temperature and density - show top hat profiles at the first $x$-station at $x / D=2$ and progressive change towards the Gaussian profile. Among the 3 data sets, the temperature data are the noisiest. The uncertainty level increases significantly beyond about 7.5D downstream distance. The reason lies with an increase in the number of particles passing through the probe volume. It has been pointed out earlier that the clean air supply hood extends about 7.5D from the nozzle exit, after which particle laden room air progressively mixes with the main airflow. However, the particles are still few as reflected in the total scattered light used for density measurement. Kourous and Seasholtz ${ }^{16}$ have demonstrated that velocity and temperature information can be reliably extracted when the flow is laden with a large number of particles. When there are only occasional particles and a scanning Fabry-Perot is used to resolve the Rayleigh spectrum, such as in the present situation, uncertainty level in temperature measurement significantly increases. The reason lies with the ability to model the particle light. A large number of particles produce a continuous distribution that is spread around the peak in the Rayleigh spectrum and is separable from the molecular scattered light. In contrast, an occasional particle affects only the spectral part acquired at the instance of particle passing, and 
therefore, a suitable modeling of the particle scattered light becomes impossible. The outcome is the increased level of uncertainty in temperature measurement as seen in the profile obtained at $\mathrm{x} / \mathrm{D}=10$ in Fig. 10 (b).

The centerline and radial surveys in the supersonic plumes of $\mathrm{M}=1.4$ and 1.8 C-D nozzles are shown in the figures 11 through 14 . Note that the data were obtained at the least shock operating conditions of respectively, $\mathrm{M}=1.395$ and 1.795 . The least shock operating conditions were determined from the centerline density surveys (similar to Figs. $11 \& 13$ ) made at various pressure ratio conditions. Since, density measurement is most accurate among the three, periodic modulations from the shock cells can be clearly identified from this data set. It should be pointed put that the data presented in Figs. 11 through 14 are from an earlier setup that used an Argon-ion laser. Occasional mode hops encountered in that laser operation has caused higher uncertainty level in velocity measurements in a few stray data points. Figs. 11(c ) and 13(c ) show the presence of weak cell patterns, consisting of compression and expansion waves, in the initial region of the jet plumes. Such patterns are not clearly discernable in the velocity and temperature data due to the random uncertainty. The shock cell patterns are somewhat stronger in the $\mathrm{M}=1.4$ jet, where the radial profiles (Fig. 12) also show distortions due to the shock cells. In a perfectly expanded jet, the radial profiles close to the nozzle exit are expected to be top hat in shape; presence of any shock cell causes distortion of the uniform part. Noticeably random uncertainty in the temperature data, at the farthest downstream stations for both supersonic jet cases, are not as high as for the $\mathrm{M}=.99$ jet. The reason lies with the slower spreading rate expected with an increase in the Mach number, which in turn reduces the number of entrained particles.

\section{SUMMARY}

A Rayleigh scattering setup using the green line from a CW Argon-ion laser, a scanning FabryPerot interferometer and photon counting electronics were setup to perform point measurements in high-speed jet flow fields. The fundamental principle and an outline of the measurement process are described. To alleviate problems associated with high noise levels emitted by the jets the laser light source was placed in an a anechoic box and the Fabry-Perot interferometer with the associated optics was moved to an adjoining test cell that provided a quiet environment. Light transmission was performed through fiber-optic cables. To avoid problems associated with particle scattering filtered air was used for both the primary flow and in the immediate neighborhood of the jet. From measurements performed under known flow conditions, uncertainties in velocity measurement is established as $\pm 10 \mathrm{~m} / \mathrm{s}$. The measured temperature is found to be lower by $8^{\circ} \mathrm{K}$ with a superimposed random uncertainty of $\pm 8^{\circ} \mathrm{K}$.

Two axisymmetric convergent-divergent (C-D) nozzles with operating Mach numbers 1.4 and 1.8 were designed and fabricated. The plumes from these two C-D nozzles and a third case involving a convergent nozzle operated at $\mathrm{M}=0.99$ were surveyed using the Rayleigh scattering technique. In addition to the velocity and temperature data earlier density measurements performed in the same plumes are presented in this paper. The centerline decay characteristics and the radial profiles obtained up to a downstream distance of 15 nozzle diameters are expected to be valuable for computational fluid dynamics code validation.

\section{References}

${ }^{1}$ Eggins, P. L. \& Jackson, D. A. 1974 Laser-Doppler velocity measurements in under-expanded free jet. J. Phys. D: Appl. Phys. 7, 1894-1906.

${ }^{2}$ Ross, C., Lourenco. L. M., and Krothapalli, A. 1994 Particle image velocimetry measurements in a shock-containing supersonic flow. AIAA 94-0047.

${ }^{3}$ Wernet, M. P. 1995 Fuzzy inference enhanced information recovery from digital PIV using crosscorrelation combined with particle tracking. NASA TM 106896. 
${ }^{4}$ Forkey, J. N., Lempert, W. R. and Miles, R. B., "Accuracy limits for planer measurements of flow field velocity, temperature and pressure using filtered Rayleigh Scattering," Experiments in Fluids, Vol. 24, 1998, pp.151-162.

${ }^{5}$ Elliott, G. S. \& Samimy, M. 1996 Rayleigh scattering technique for simultaneous measurements of velocity and thermodynamic properties. AIAA J., 34 (11), 2346-2352.

${ }^{6}$ Seasholtz, R. G., Buggele, A. E. and Reeder, M. F., "Flow measurements based on Rayleigh scattering and Fabry-Perot interferometer," Optics and Lasers in Engineering, Vol. 27, pp. 543-570.

${ }^{7}$ Seasholtz, R. G., Zupanc, F. J. \& Schneider, S. J. 1992 Spectrally resolved Rayleigh scattering diagnostic for hydrogen-oxygen rocket plume studies. J. Propulsion \& Power, 8(5), 935-942.

${ }^{8}$ Snyder, S. C., Reynolds, L. D., Lassahn, G. D., Fincke, J. R., Shaw, G. B., Jr. and Kearney, R. J., "Determination of gas-temperature and velocity profiles in an argon thermal-plasma jet by laser light scattering," Physical Review E, Vol. 47, no. 3, 1993, pp. 1997-2005.

${ }^{9}$ Pitz, R. W., Cattolica, R. Robben, F. and Talbot, L., "Temperature and density in a Hydrogen-Air flame from Rayleigh scattering," Combustion and Flame, Vol. 27, no. 3, 1976, pp. 313-320.

${ }^{10}$ Lock, J. A., Seasholtz, R. G. \& John, W. T. 1992 Rayleigh-Brillouin scattering to determine onedimensional temperature and number density profiles of a gas flow jet. Appl. Opt., 31(15), 28392848.

${ }^{11}$ Panda, J. and Seasholtz, R. G., " Density measurements in underexpanded supersonic jets using Rayleigh scattering," AIAA paper no. 980281, 1998.

${ }^{12}$ Panda, J. and Seasholtz, R. G., " Density fluctuation measurement in supersonic fully expanded jets using Rayleigh scattering. AIAA 991870, 1999.

${ }^{13}$ Tenti, G., Boley, C. D. and Desai, R. C., "On the kinetic model description of Rayleigh-Brillouin scattering from molecular gases," Canadian J. of Physics, vol. 52, no. 4, Feb. 1974, pp. 285-290.
${ }^{14}$ Vaughan, J. M., The Fabry-Perot Interferometer, History, Theory, Practice and Applications. Adam Hilger, Bristol, 1989.

${ }^{15}$ Hernandez, G., Fabry-Perot Interferometers, Cambridge University Press, Cambridge, UK 1986.

${ }^{16}$ Kourous, H. E. and Seasholtz, R. G., "Fabry-Perot interferometer measurement of static temperature and velocity for ASTOVL model tests, NASA TM 107014, 1994.

Table I. Operating conditions

\begin{tabular}{|c|c|c|c|}
\hline \multicolumn{2}{|l|}{ Sp. heat ratio, $\gamma$} & \multicolumn{2}{|c|}{1.4} \\
\hline \multicolumn{2}{|l|}{ Total temp., $\mathrm{T}_{0}$} & \multicolumn{2}{|c|}{$300^{\circ} \mathrm{K}$} \\
\hline \multicolumn{2}{|l|}{ Ambient temp., $\mathrm{T}_{\mathrm{a}}$} & \multicolumn{2}{|c|}{$297^{\circ} \mathrm{K}$} \\
\hline Ambient density, $\rho_{a}$ & & \multicolumn{2}{|c|}{$1.16 \mathrm{Kg} / \mathrm{m}^{3}$} \\
\hline \multirow[t]{2}{*}{ Ambient Pressure, $\mathrm{P}_{\mathrm{a}}$} & & \multicolumn{2}{|c|}{$98.95 \mathrm{KPa}$} \\
\hline & $\begin{array}{l}\mathrm{M}=0.99 \\
\text { Conv. } \\
\text { Nozzle }\end{array}$ & $\begin{array}{l}\mathrm{M}=1.4 \\
\text { nozzle }\end{array}$ & $\begin{array}{l}\mathrm{M}=1.8 \\
\text { nozzle }\end{array}$ \\
\hline Minimum shock at $\mathrm{M}=$ & -- & 1.395 & 1.795 \\
\hline $\begin{array}{l}\text { Plenum pressure, } \mathrm{P}_{0} \\
(\mathrm{KPa})\end{array}$ & 185.1 & 312.7 & 564.2 \\
\hline Jet density, $\rho_{\mathrm{j}}\left(\mathrm{Kg} / \mathrm{m}^{3}\right)$ & 1.37 & 1.6 & 1.89 \\
\hline Static temp, $\mathrm{T}_{\mathrm{j}}\left({ }^{\circ} \mathrm{K}\right)$ & 251 & 216 & 182.4 \\
\hline Jet velocity, $U_{j}(\mathrm{~m} / \mathrm{s})$ & 314 & 411 & 486 \\
\hline
\end{tabular}




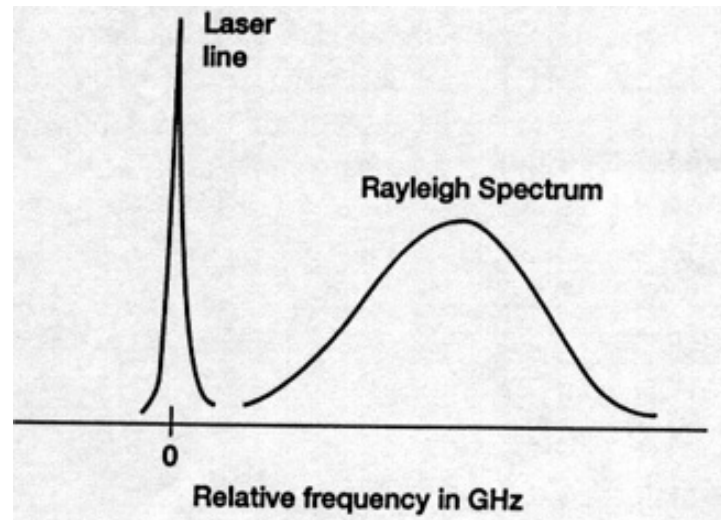

Fig. 1. Schematic to explain principle of Rayleigh scattering technique.

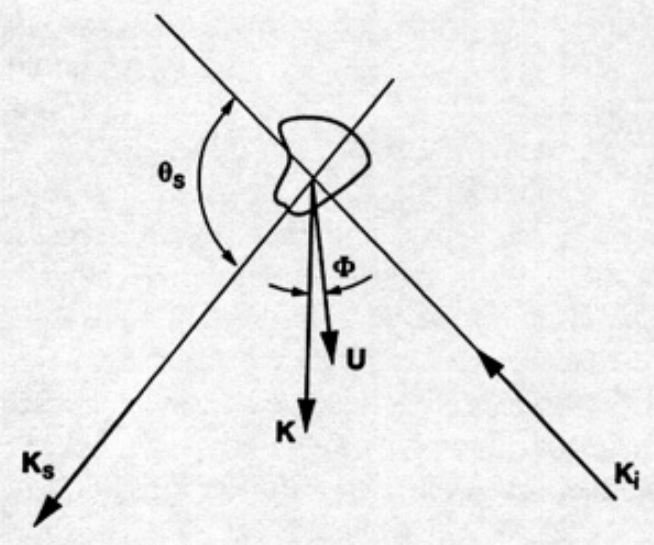

Figure 2 Scattering diagram for the Rayleigh scattering arrangement.

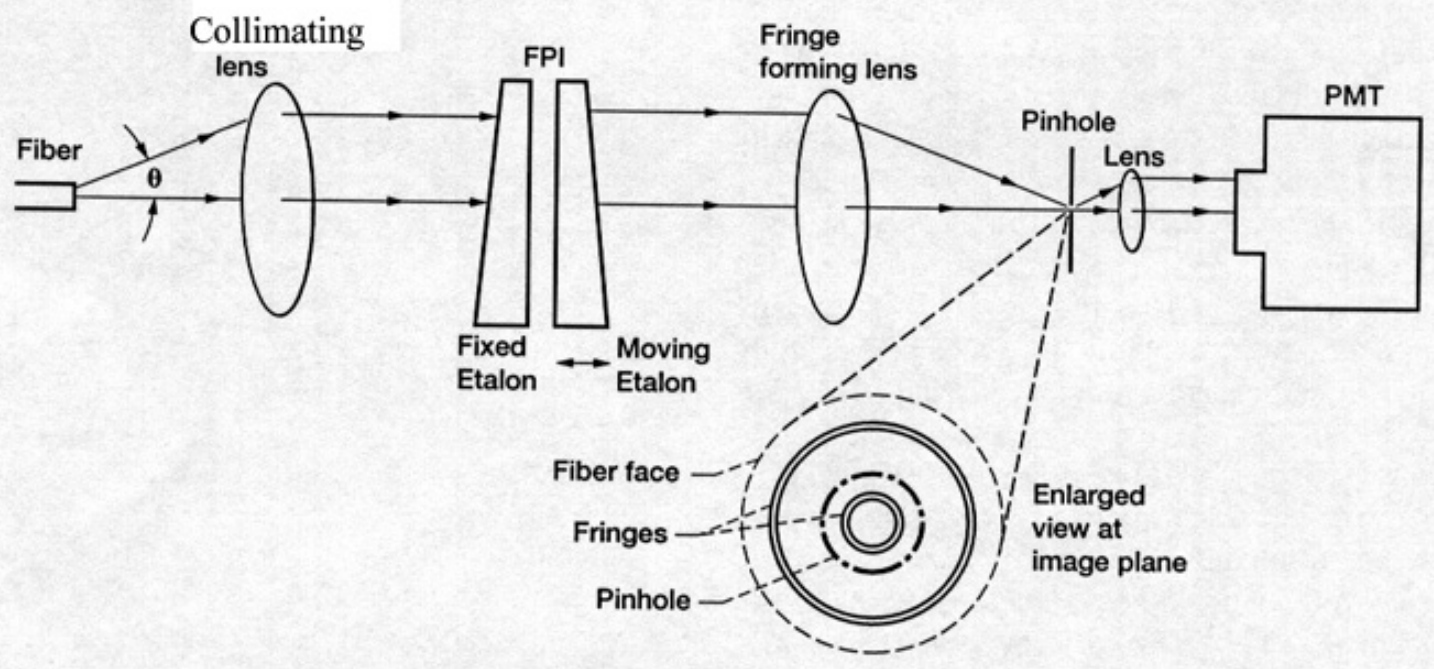

Figure 3.-Imaging through a scanning Fabry-Perot interferometer. 
TableII. Nozzle coordinates.

\begin{tabular}{|c|c|c|c|}
\hline \multicolumn{2}{|c|}{$\mathrm{M}=1.8 \mathrm{CD}$ nozzle } & \multicolumn{2}{|c|}{$\mathrm{M}=1.4 \mathrm{CD}$ nozzle } \\
\hline$x$ (inches) & radius ( $r$,inches) & $\mathrm{x}$ (inches) & $r$ (inches) \\
\hline-5.0 & 1.5 & -4.926 & 1.5 \\
\hline-3.773 & 1.338 & -4.366 & 1.482 \\
\hline-2.593 & 0.962 & -3.905 & 1.437 \\
\hline-2.157 & 0.752 & -3.444 & 1.368 \\
\hline-2.049 & 0.691 & -2.938 & 1.257 \\
\hline-1.943 & 0.624 & -2.487 & 1.132 \\
\hline-1.761 & 0.511 & -2.082 & 0.992 \\
\hline-1.662 & 0.47 & -1.602 & 0.789 \\
\hline-1.535 & 0.436 & -1.356 & 0.664 \\
\hline-1.464 & 0.425 & -1.148 & 0.552 \\
\hline-1.391 & 0.4188 & -0.98 & 0.499 \\
\hline-1.361 & 0.4181 & -0.82 & 0.4763 \\
\hline-1.327 & 0.4183 & -0.786 & 0.4751 \\
\hline-1.297 & 0.419 & -0.749 & 0.4749 \\
\hline-1.244 & 0.422 & -0.735 & 0.475 \\
\hline-1.189 & 0.428 & -0.72 & 0.4755 \\
\hline-1.161 & 0.431 & -0.685 & 0.4772 \\
\hline-1.118 & 0.436 & -0.66 & 0.4786 \\
\hline-1.076 & 0.441 & -0.635 & 0.4798 \\
\hline-1.033 & 0.446 & -0.575 & 0.4821 \\
\hline-0.883 & 0.46 & -0.546 & 0.4834 \\
\hline-0.777 & 0.47 & -0.489 & 0.4863 \\
\hline-0.663 & 0.479 & -0.468 & 0.4871 \\
\hline-0.577 & 0.485 & -0.379 & 0.4895 \\
\hline-0.505 & 0.489 & -0.255 & 0.4938 \\
\hline-0.289 & 0.498 & -0.145 & 0.4982 \\
\hline 0.0 & 0.501 & 0.0 & 0.501 \\
\hline
\end{tabular}

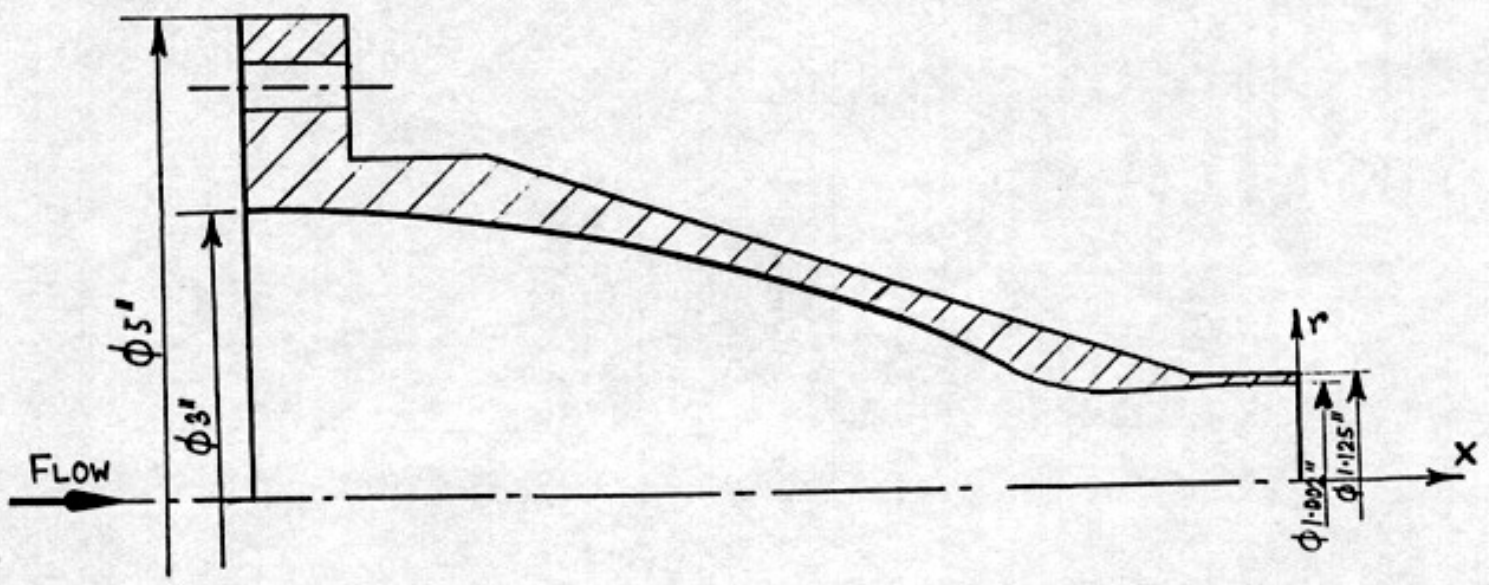

Fig.4. Schematic of the nozzle block. Coordinates of the inside contour are provided in Table II. 


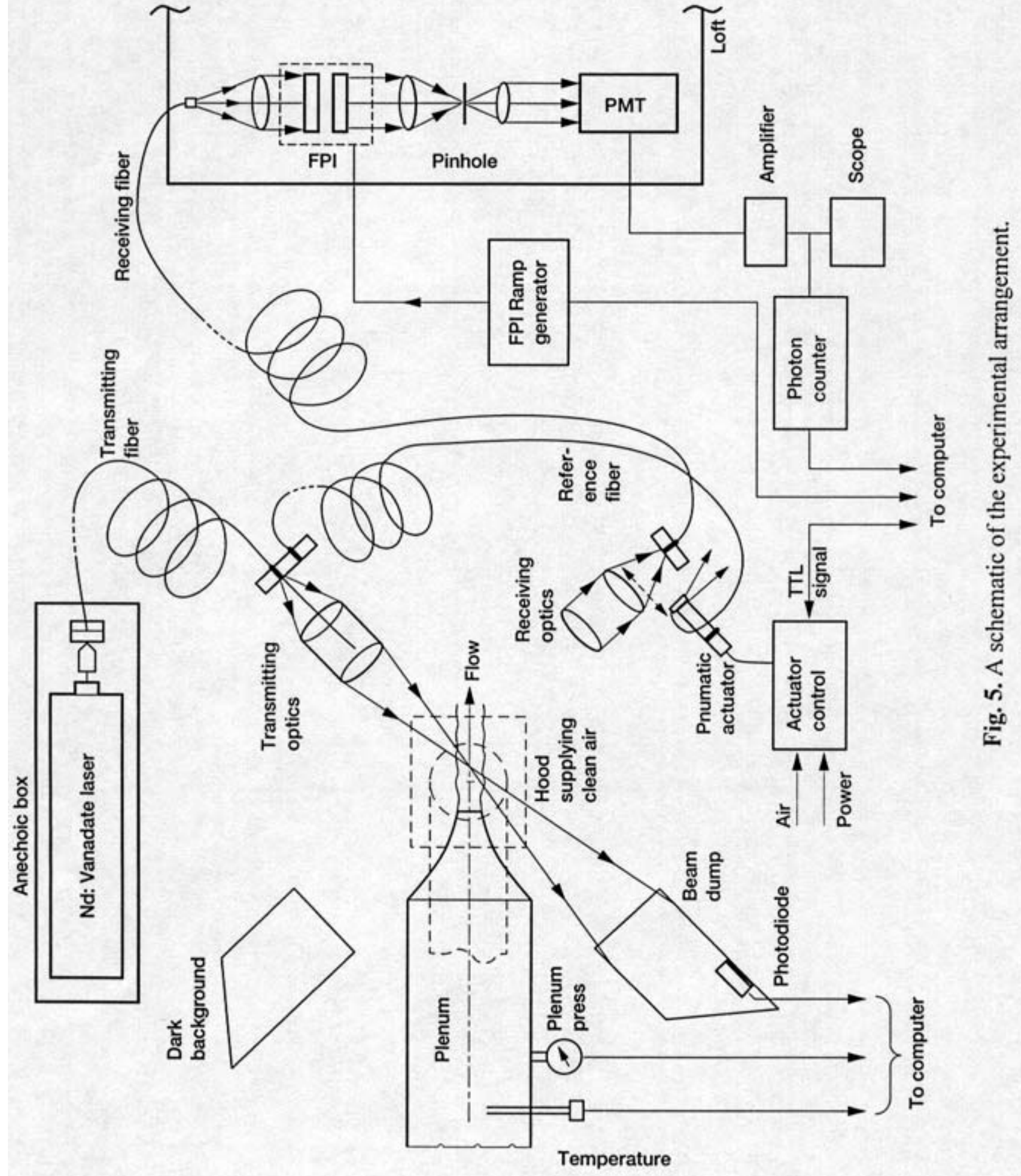




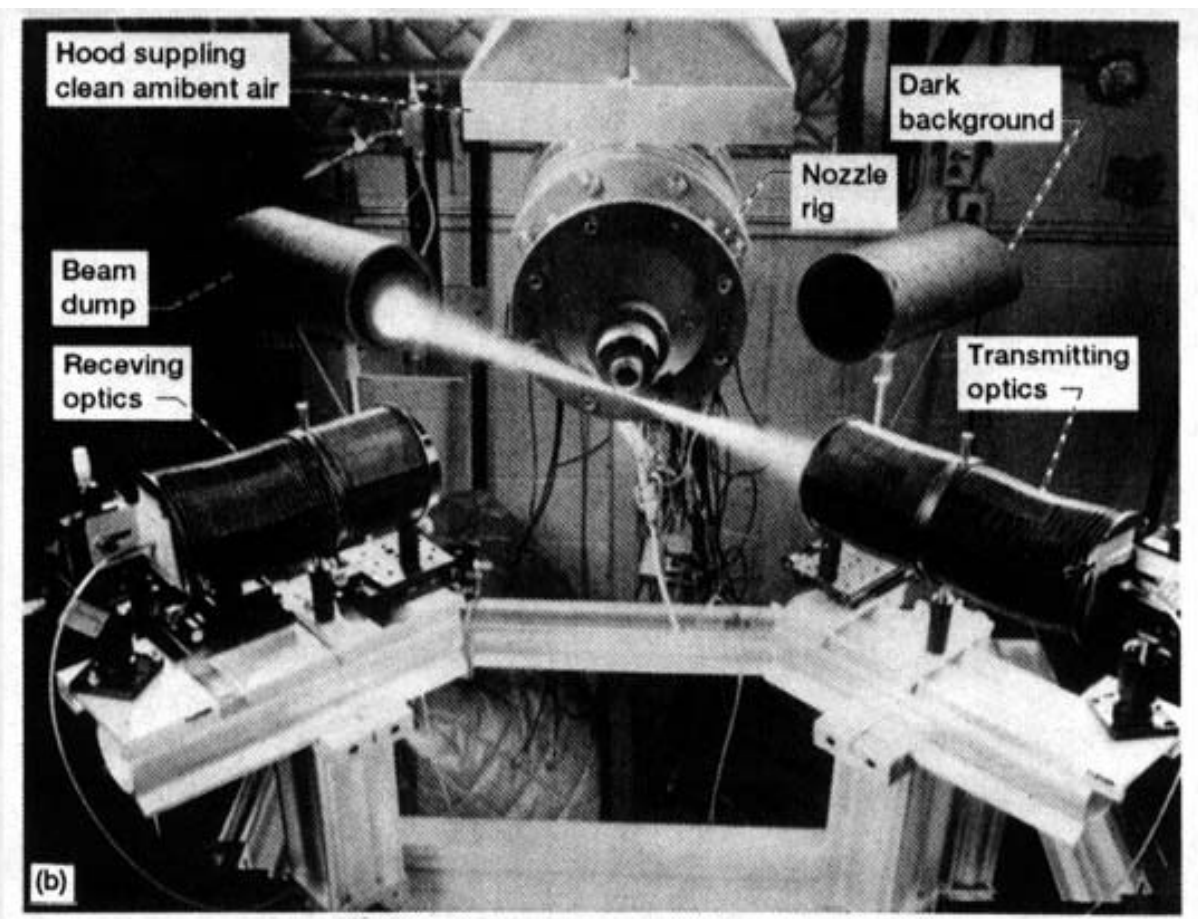

Fig. 6. Photograph of arrangement around jet facility.

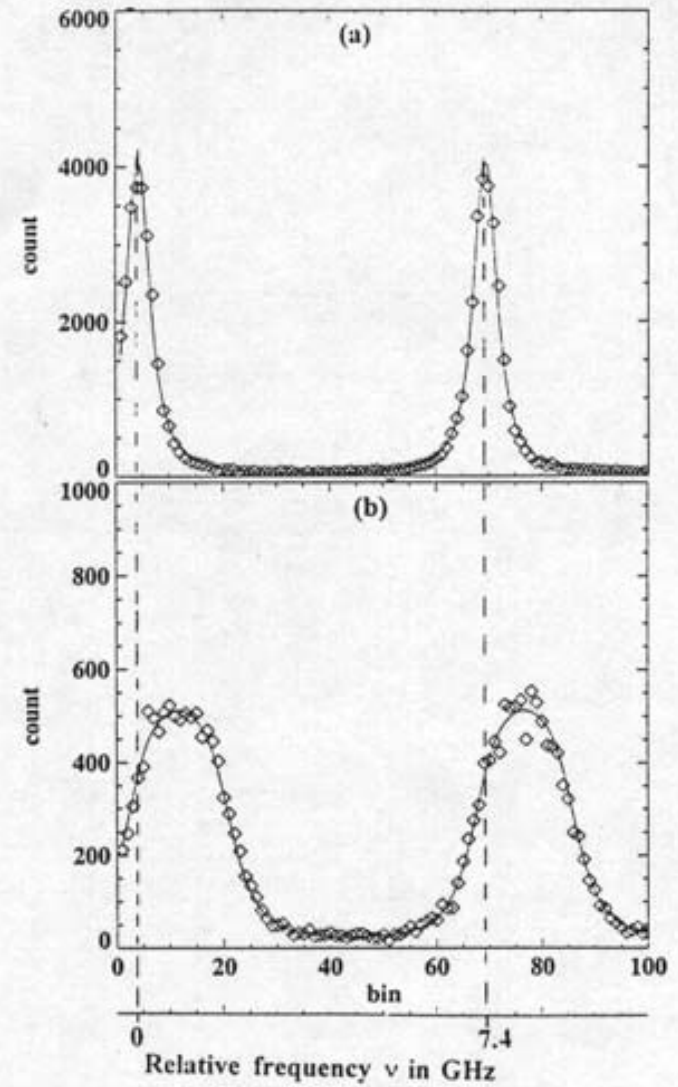

Fig. 7. Sample of (a) reference (b) Rayleigh scattering spectra (centerline $\mathrm{M}=0.99$ jet); solid line: fitted model function, symbols: experimental data.
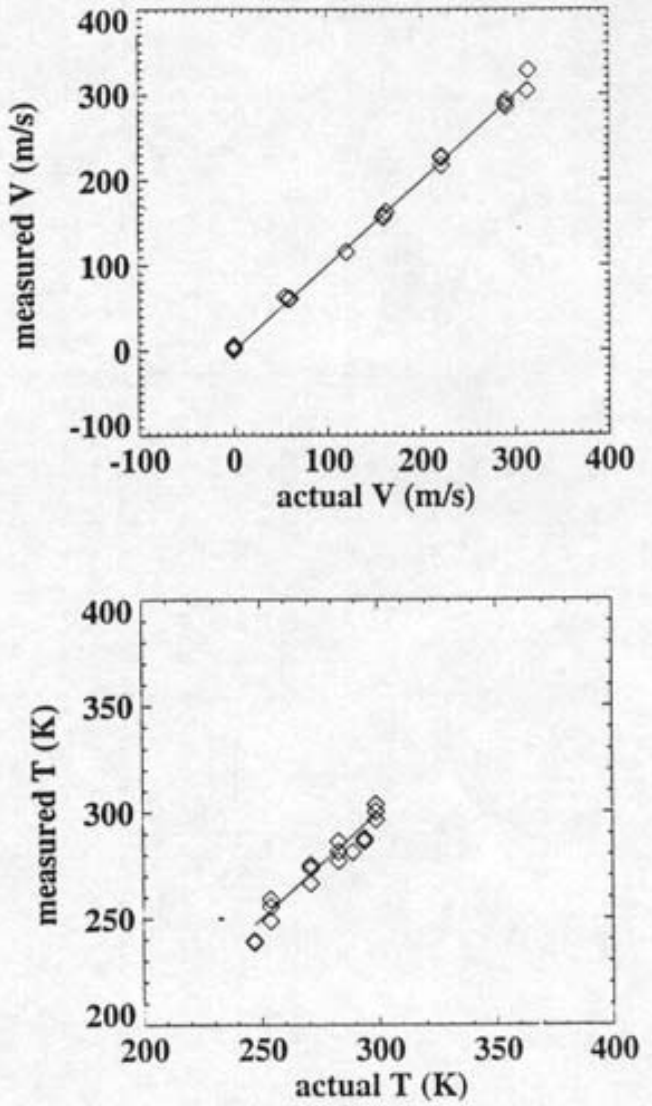

Fig. 8. A comparison between measured (symbols) and expected (solid line) variation in $\mathrm{M}=0$ to 1 range. 

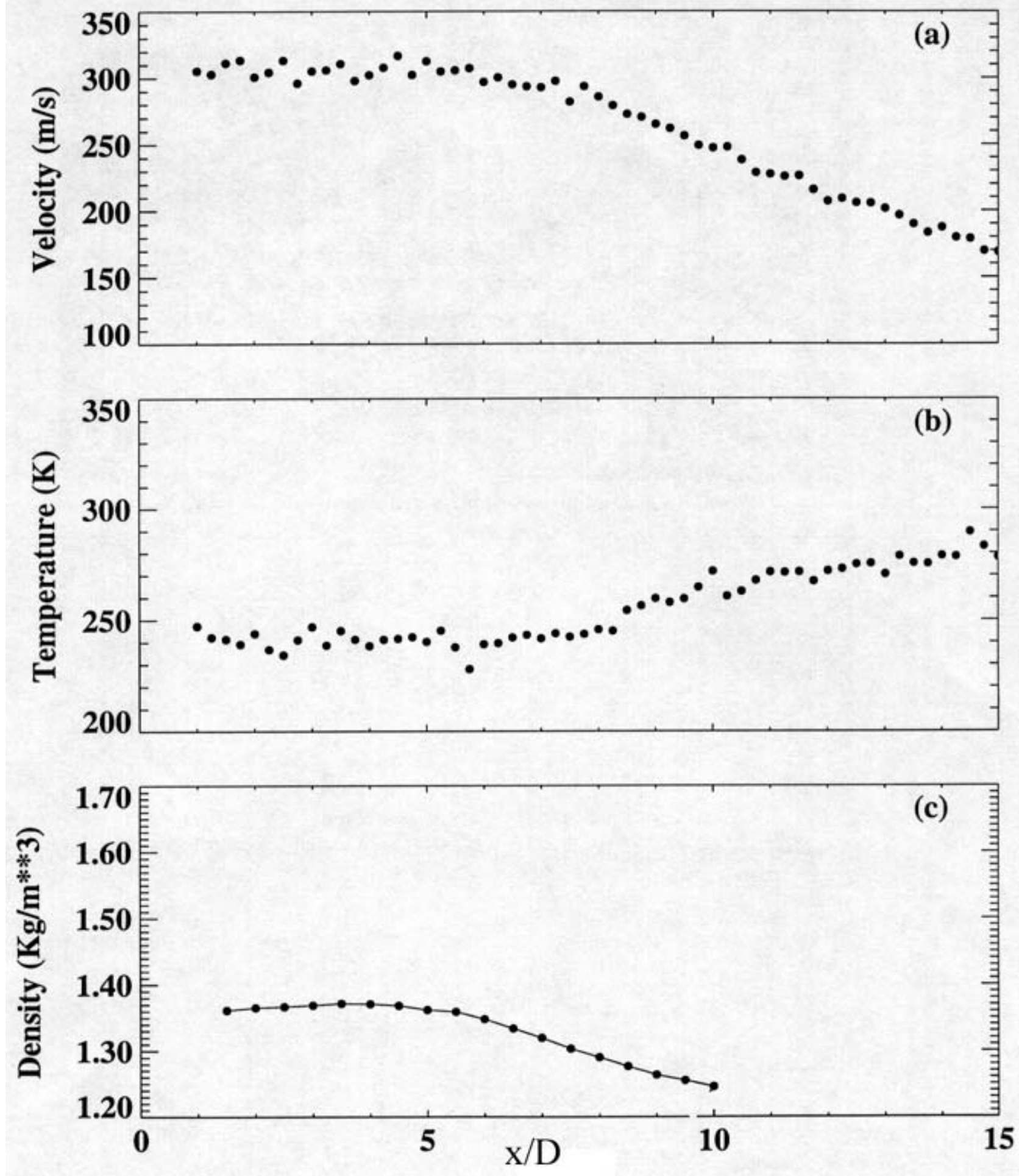

Fig. 9. Centerline variations in $\mathrm{M}=0.99$ jet 

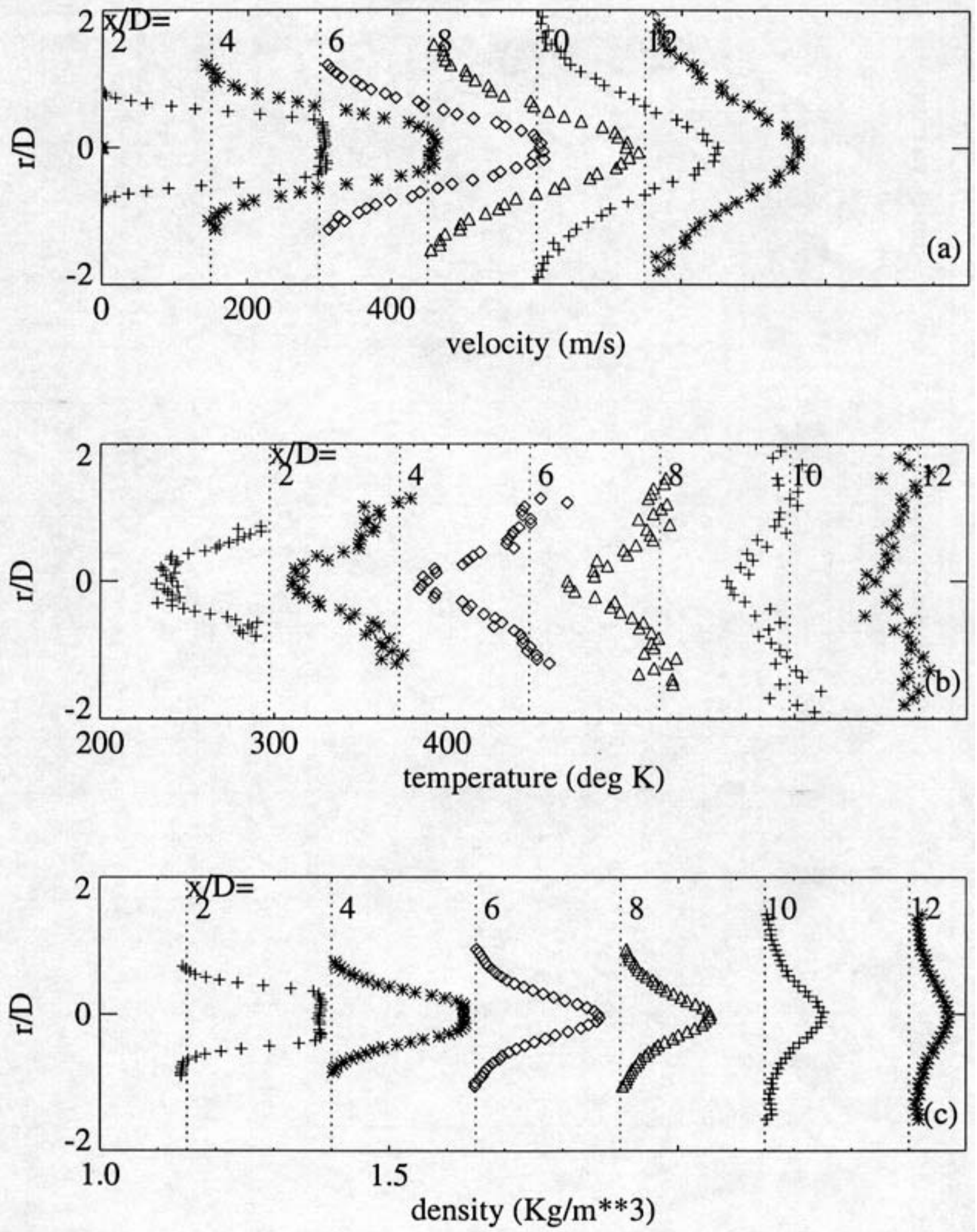

Fig. 10. Radial profiles from indicated axial stations in $M=0.99$ jet. The chained lines indicate ambient condition. Each profile is separated by the distance between 2 chained lines. 

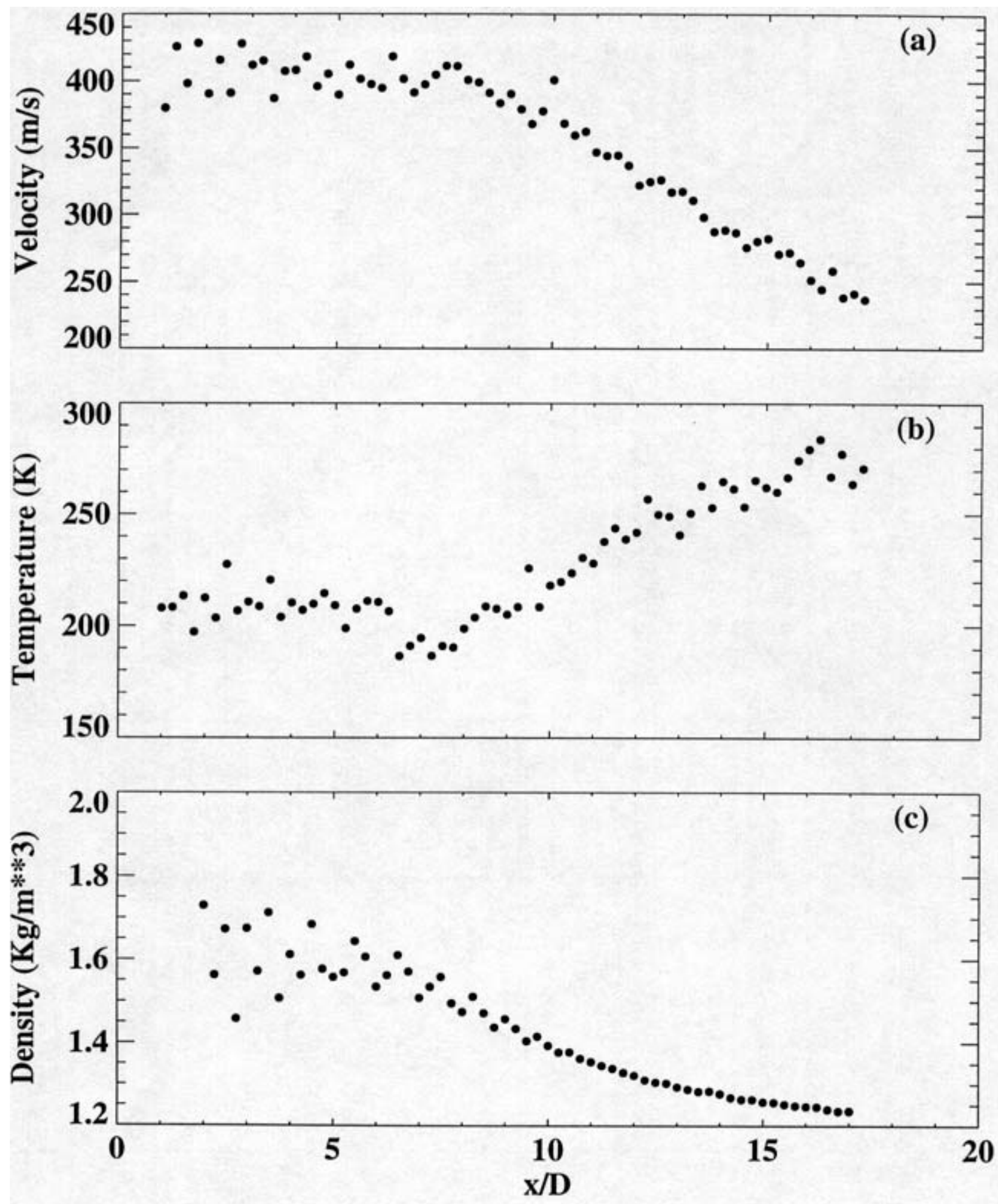

Fig. 11. Centerline variations in $M=1.395$ jet from a C-D nozzle. 

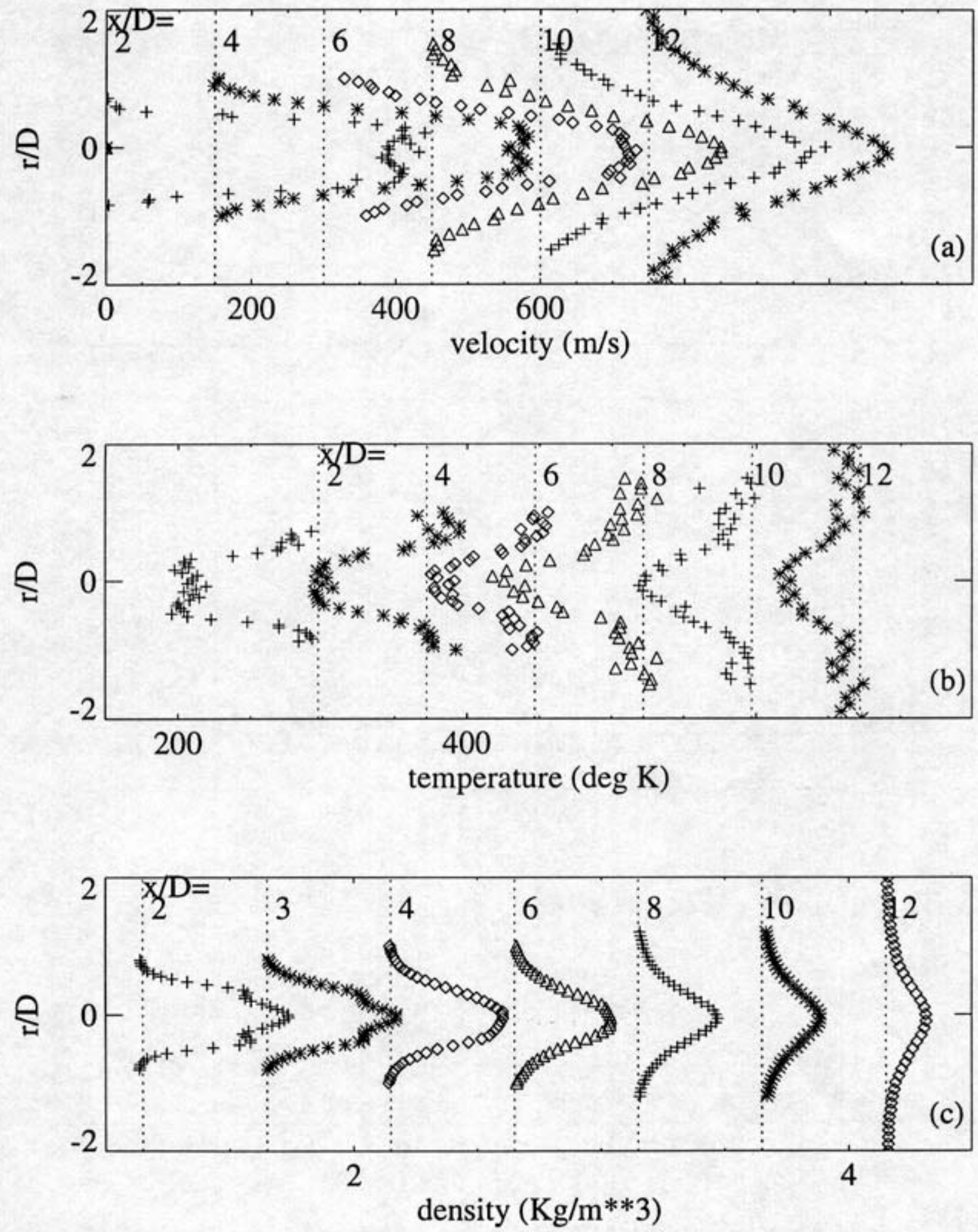

Fig. 12. Radial profiles from indicated axial stations in $M=1.395$ jet. The chained lines indicate ambient condition. 

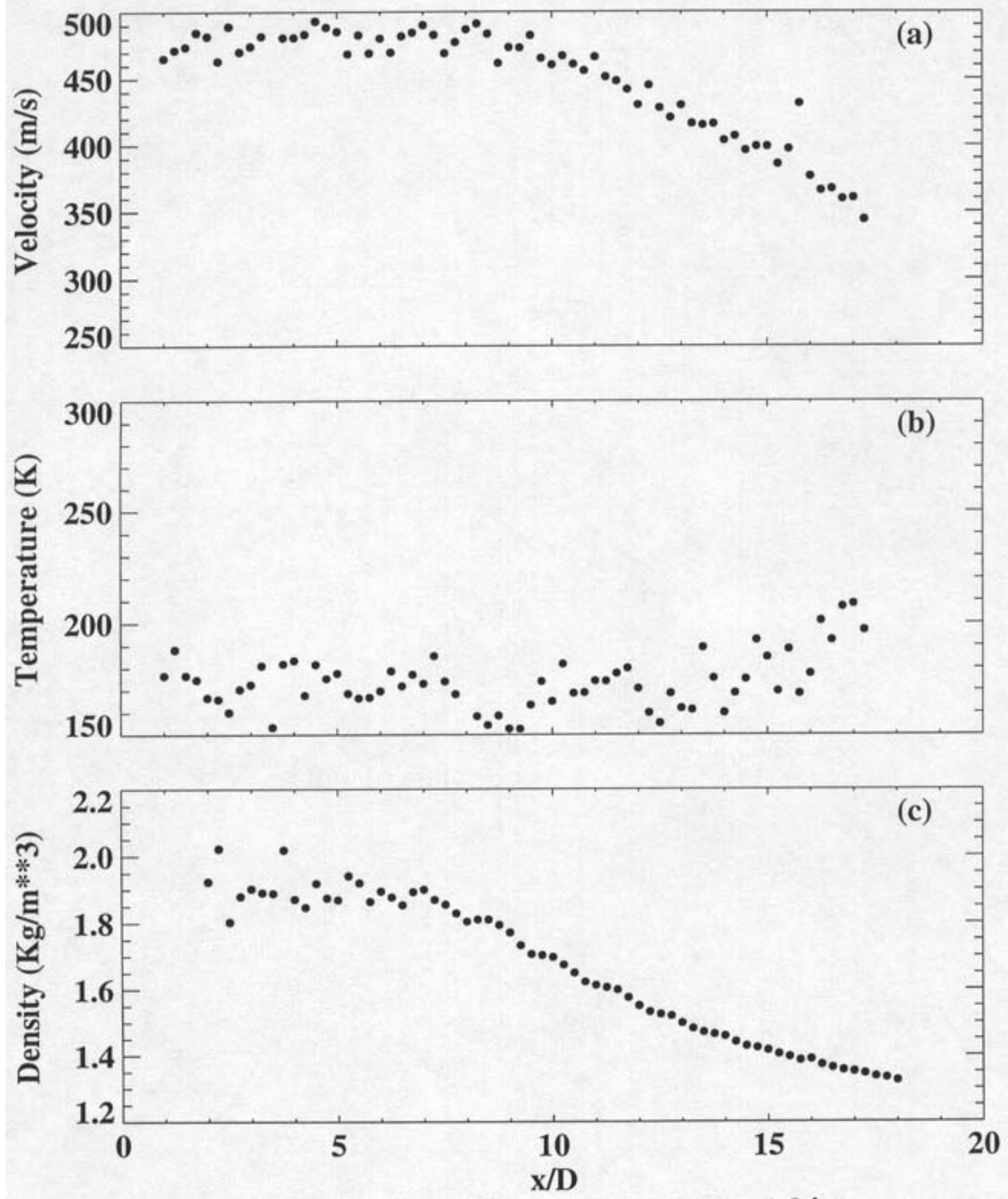

Fig. 13. Centerline variations in $M=1.8$ jet

Note (added after publication): The centerline temperature decay of Fig. 13(b) has significantly higher uncertainty due to slight condensation in the jet. All other data have uncertainty mentioned in the text. 

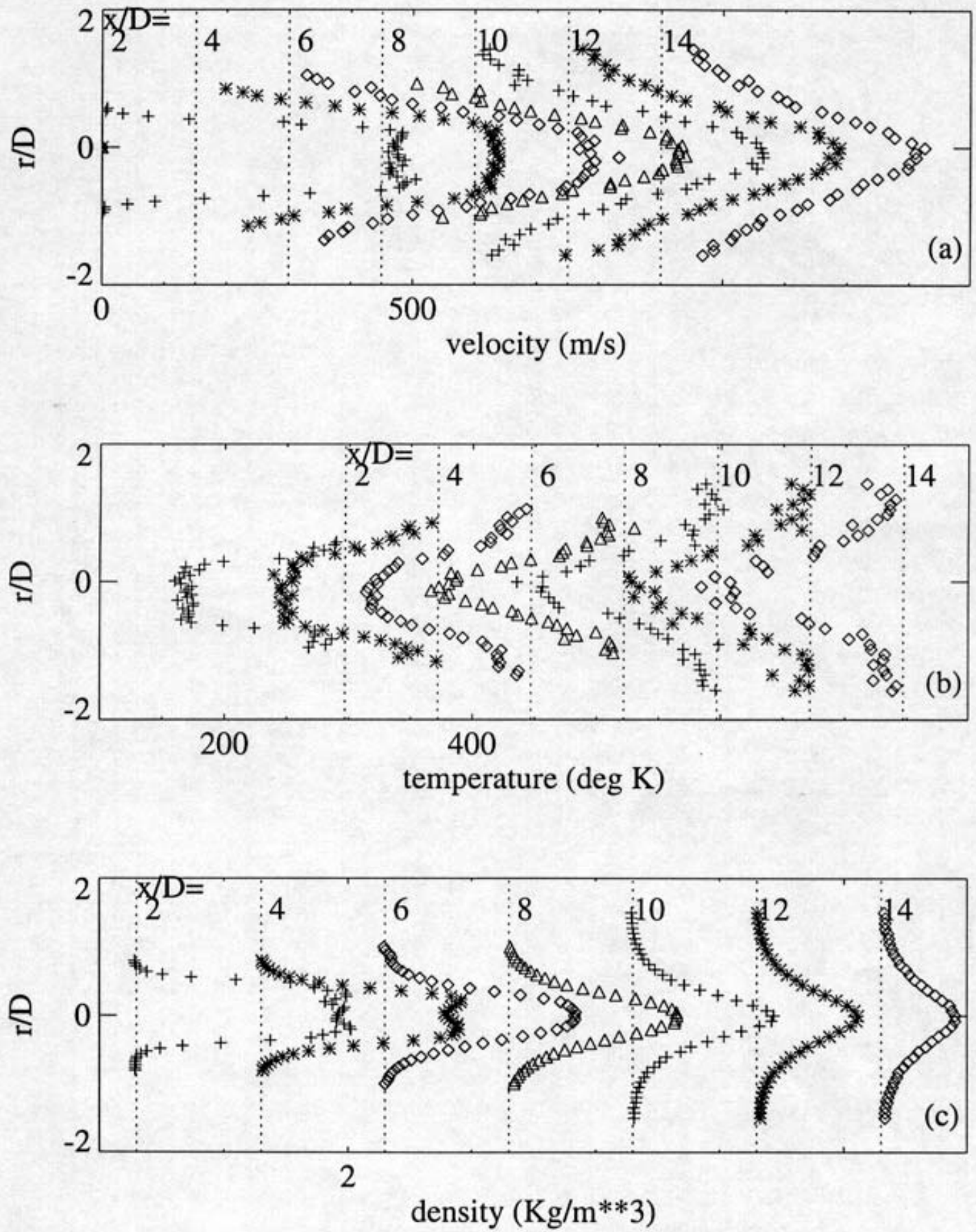

Fig. 14. Radial profiles from indicated axial stations in $M=1.8$ jet. The chained lines indicate ambient condition.

Note (added after publication): The temperature profiles of Fig. 14(b) have significantly higher uncertainty due to slight condensation in the jet. All other data have uncertainty mentioned in the text. 
Public reporting burden for this collection of information is estimated to average 1 hour per response, including the time for reviewing instructions, searching existing data sources, gathering and maintaining the data needed, and completing and reviewing the collection of information. Send comments regarding this burden estimate or any other aspect of this collection of information, including suggestions for reducing this burden, to Washington Headquarters Services, Directorate for Information Operations and Reports, 1215 Jefferson Davis Highway, Suite 1204, Arlington, VA 22202-4302, and to the Office of Management and Budget, Paperwork Reduction Project (0704-0188), Washington, DC 20503.

\begin{tabular}{|l|l|r|}
\hline 1. AGENCY USE ONLY (Leave blank) & $\begin{array}{c}\text { 2. REPORT DATE } \\
\text { May } 2004\end{array}$ & $\begin{array}{r}\text { 3. REPORT TYPE AND DATES COVERED } \\
\text { Technical Memoran }\end{array}$
\end{tabular}

\section{TITLE AND SUBTITLE}

May 2004

5. FUNDING NUMBERS

Velocity and Temperature Measurement in Supersonic Free Jets Using Spectrally

Resolved Rayleigh Scattering

6. AUTHOR(S)

J. Panda and R.G. Seasholtz

WBS-22-714-08-14

7. PERFORMING ORGANIZATION NAME(S) AND ADDRESS(ES)

National Aeronautics and Space Administration

John H. Glenn Research Center at Lewis Field

Cleveland, Ohio 44135-3191

8. PERFORMING ORGANIZATION

REPORT NUMBER

E-13968

9. SPONSORING/MONITORING AGENCY NAME(S) AND ADDRESS(ES)

National Aeronautics and Space Administration

Washington, DC 20546-0001

10. SPONSORING/MONITORING

AGENCY REPORT NUMBER

NASA TM-2004-212391

AIAA-99-0296

11. SUPPLEMENTARY NOTES

Prepared for the 37th Aerospace Sciences Meeting and Exhibit sponsored by the American Institute of Aeronautics and

Astronautics, Reno, Nevada, January 11-14, 1999. J. Panda, Modern Technologies Corporation, Middleburg Heights, Ohio 44130 and Resident Research Associate at Glenn Research Center (presently with Ohio Aerospace Institute, Brook Park, Ohio 44142); R.G. Seasholtz, NASA Glenn Research Center. Responsible person, R.G. Seasholtz, organization code 5520, 216-433-3754.

\begin{tabular}{|l|l} 
12a. DISTRIBUTION/AVAILABILITY STATEMENT & 12b. DISTRIBUTION CODE
\end{tabular}

Unclassified - Unlimited

Subject Category: 07

Distribution: Nonstandard

Available electronically at http://gltrs.grc.nasa.gov

This publication is available from the NASA Center for AeroSpace Information, 301-621-0390.

13. ABSTRACT (Maximum 200 words)

The flow fields of unheated, supersonic free jets from convergent and convergent-divergent nozzles operating at $\mathrm{M}=0.99$, 1.4, and 1.6 were measured using spectrally resolved Rayleigh scattering technique. The axial component of velocity and temperature data as well as density data obtained from a previous experiment are presented in a systematic way with the goal of producing a database useful for validating computational fluid dynamics codes. The Rayleigh scattering process from air molecules provides a fundamental means of measuring flow properties in a non-intrusive, particle free manner. In the spectrally resolved application, laser light scattered by the air molecules is collected and analyzed using a Fabry-Perot interferometer (FPI). The difference between the incident laser frequency and the peak of the Rayleigh spectrum provides a measure of gas velocity. The temperature is measured from the spectral broadening caused by the random thermal motion and density is measured from the total light intensity. The present point measurement technique uses a $\mathrm{CW}$ laser, a scanning FPI and photon counting electronics. The $1 \mathrm{~mm}$ long probe volume is moved from point to point to survey the flow fields. Additional arrangements were made to remove particles from the main as well as the entrained flow and to isolate FPI from the high sound and vibration levels produced by the supersonic jets. In general, velocity is measured within $\pm 10 \mathrm{~m} / \mathrm{s}$ accuracy and temperature within $\pm 10 \mathrm{~K}$ accuracy.

14. SUBJECT TERMS

Rayleigh scattering; Supersonic jets; Jet noise 15. NUMBER OF PAGES 25

\begin{tabular}{|c|c|c|}
\hline $\begin{array}{c}\text { 17. SECURITY CLASSIFICATION } \\
\text { OF REPORT } \\
\text { Unclassified }\end{array}$ & $\begin{array}{c}\text { 18. SECURITY CLASSIFICATION } \\
\text { OF THIS PAGE } \\
\text { Unclassified }\end{array}$ & $\begin{array}{c}\text { 19. SECURITY CLASSIFICATION } \\
\text { OF ABSTRACT } \\
\text { Unclassified }\end{array}$ \\
\hline
\end{tabular}

NSN 7540-01-280-5500

Standard Form 298 (Rev. 2-89)

Prescribed by ANSI Std. Z39-18 298-102 

